\title{
Paul Stortz and E. Lisa Panayotidis, eds. Cultures, Communities, and Conflict: Histories of Canadian Universities and War
}

Toronto: University of Toronto Press, 2012. 321pp.

\author{
Jonathan F. Vance \\ Western University
}

Universities, write Paul Stortz and Lisa Panayotidis in their introduction, are "socio-intellectual and academic spaces and places devoted to the production, examination, and dissemination of ideas" (18). Yet historically, and indeed until relatively recently, the university has often been regarded as distinct from its society - the enclosed quadrangle that was locked at dusk had a practical purpose, but perhaps even more important was the symbolism of distinguishing the place of the mind from the place of the body.

The collection sets out to challenge some of these established presumptions, such as "the stereotype of the university as an elite 'ivory tower' divorced from the realities of regional or national life" and "the 'town and gown' view of the university as an academic cloister or island radically distinct in character and values from the community that surrounds it" (9). On the contrary, a number of the authors reveal how little distance there was between the views of town and gown on some of the key issues in wartime - whether it be the rhetoric of sacrifice at Acadia or the discourse of manliness at Saskatchewan. "If universities aspire to scholarly detachment from the affairs of everyday life," write Paul Axelrod and Charles Levi, "the illusion that this is possible in wartime quickly dissipates" (265).

An interesting commonality to these articles is that they tend to be written from the "gown" end of things. In Michiel Horn's discussion of academic freedom in wartime, we learn about meddlesome politicians and community leaders seeking to have certain faculty members dismissed for their public statements. Donald Avery's article on Canadian university scientists and military technology in the Second World War reveals government officials arriving on campus with hefty cheques to pay for research. But beyond such specific, practical interactions, there is little sense of how any 
city or town perceived the university within it, or how Canadians in a broader sense regarded their universities. The articles generally look outward from campus, rather than towards campus from the outside.

As with any edited collection, this one points to many other avenues of enquiry. What of the role of alumni networks in wartime? Were the connections forged as undergraduates strengthened and mobilized during wartime? What about ethnic minorities on campus? Paul Stortz writes of refugee professors at the University of Toronto, but from the perspective of their refugee status rather than their ethnicity. In that the collection is more about universities during wartime than it is about the impact of war on universities, it has relatively little to say about the postwar decades and how the aftermath of war continued to exert a profound influence on academe. What about pacifism on campus in the 1930s? One of the curiosities of the subject is how rapidly the fervent and passionate campus pacifism of the late 1930s gave way to a rush to enlist in the early 1940s. Equally significant was the massive impact of Second World War veterans on universities in the late 1940s and 1950s.

More broadly, it would have been useful to learn something of the demographic changes that war brought to university campuses over the course of the twentieth century. The editors suggest that war helped Canadian universities to alter their character as largely male bastions of white, Anglo-Saxon privilege and become more diverse, socially and culturally. In this sense, they have become more reflective of Canadian society as a whole. But in embracing the positive aspects of social transformation, did they also take on some of the negative aspects of post-1945 Canadian society, such as apathy and self-absorption? In this regard, Catherine Gidney's concluding article on teach-ins at the University of Toronto in the 1960s provides food for thought. She shows us a committed group of students, faculty, and administrators coming together to raise awareness of the great issues of the era, such as religion in international affairs, coexistence with or containment of China, and the population explosion. Although the teach-in movement was short-lived, Gidney persuasively argues that it played an important role in the evolution of the campus community and of notions of a university's purpose and role in a more complicated world.

But was the University of Toronto that she sketches typical of Canadian universities in the 1960s? Were the politically engaged characters in her chapter even typical of the University of Toronto at the time? A couple of hundred kilometres west, at the University of Western Ontario in London, students reacted to the turmoil of the 1960 s — protests over the Vietnam War, including the shootings at Kent State, the escalating race riots, the mobilization of the civil rights movement - rather differently. In an era of massive upheaval, some of it right on Western's doorstep, what was the issue that most galvanized the student body and rarely slipped from the pages of the university newspaper in the 1960s? Parking. 